\title{
EDUCACIÓN A DISTANCIA Y NUEVAS TECNOLOGÍAS: LA FORMACIÓN DE DOCENTES CRÍTICOS
}

\author{
Alicia Beatriz Tedesco \\ Profesora del Liceo Víctor Mercante, Argentina \\ "El enfoque comunicativo de la Pedagogía crítica actual \\ se basa en el desarrollo del proceso de enseñanza-aprendizaje \\ a partir de la interacción entre iguales, la negociación, el \\ intercambio de significados y experiencias" Ana Yuste, 1997
}

\section{INTRODUCCIÓN}

Existen varias construcciones teóricas y paradigmas que analizan el tema de los medios y las Nuevas Tecnologías de la Información y Comunicación desde distintas perspectivas.

Estos planteos abordan principalmente los siguientes ejes:

- las diversas concepciones de los medios y las Nuevas Tecnologías en Educación, sus relaciones con las teorías del aprendizaje y la comunicación educativa;

- los modelos didácticos y comunicacionales;

- las bases psicopedagógicas, didácticas, comunicacionales y tecnológicas para la construcción de materiales multimedia, sitios web y otros recursos de las Nuevas Tecnologías y la evaluación de estos procesos en forma continua.

Construir propuestas alternativas en educación, innovadoras y creativas, es quizá el gran desafío que tienen los países de lberoamérica en el marco de la globalización y el futuro: la calidad, equidad y gestión participativa de la educación en el contexto de un mundo globalizado.

Por ello, consideramos que podemos contribuir en la Formación y Capacitación de docentes , orientando a los destinatarios para la gestión y participación en proyectos de comunicación y educación alternativos y el desarrollo de políticas educativas "glocales" con la inserción de las Nuevas Tecnologías.

El aula, presencial o virtual ,es un espacio de construcción social de conocimientos y es el docente quien desde su función como mediador y orientador, con una mirada reflexiva y crítica, puede llevar a cabo estos procesos.

Los escenarios de la Educación Continua pueden convertirse también en auténticos "semilleros" de construcción social del conocimiento.

\section{DESDE LA EDUCACIÓN PARA LOS MEDIOS HACIA EL VIAJE POR "LA NUEVA ALFOMBRA MÁGICA"}

Desde la tradicional(y no por ello menos relevante) "Educación para los medios" hasta la alfabetización en Tecnología educativa se ha atravesado un largo camino.

La Educación y las Nuevas Tecnologías compart en hoy algunos escenarios comunes.

Frente a ello el docente, formador, necesita reflexionar sobre sus propias prácticas. 
"Si dejamos que los medios de comunicación y las empresas asuman el papel de educadores subraya el Dr. Aparici-, la formación cívica de los ciudadanos quedará en manos de instituciones que no fomentan el espíritu crítico y tienden a homogeneizar las ideas." (1)

Raúl Trejo Delarbre(1996) refiriéndose a los usos y mitos de Internet, nos dice en su obra "La Nueva alfombra mágica", premiada por Fundesco:

Como Aladino, cuando nos conectamos al sistema de redes de información electrónica podemos divagar fascinados en nuestra alfombra mágica, pero corremos el riesgo de perder el rumbo, o de no entender para qué nos sirve tanta maravilla. También es posible que nos limitemos a navegar en la alfombra electrónica sin reparar en costos, o suponiendo casi que las bondades de la tecnología nos resultan accesibles por arte de magia. Las nuevas tecnologías, en este caso autopropagadas por las redes cibernéticas y los medios de comunicación convencionales, se vuelven necesarias no sólo en virtud de sus utilidades peculiares sino también a partir de requerimientos específicos que ellas mismas crean, difunden y establecen.

Aunque sea un lugar común vale decir (porque a veces no lo es tanto) que las tecnologías no son inocuas: tienen usos y llegan a ser vehículos de abusos. Son instrumentos de extensión y dominación, de civilidad y dilemas para cada nación y cada cultura, como hemos querido enfatizar en el capítulo anterior. Al filo del final del siglo, el empleo de las redes de información se está volviendo una necesidad --o al menos hay la tendencia a pensarlo así para que las naciones, las empresas y los individuos estén sintonizados con la modernidad, o con las imágenes que de ella se tienen con más frecuencia. Las nuevas tecnologías son parte del proceso de dominación-apropiación que suele existir en las relaciones económicas (y políticas incluso) en el entorno internacional que tenemos en esta era de la globalización" (2)

A través de las NTIC podemos recibir información al instante y con un "envoltorio" vistoso, inmerso en la "cultura de la apariencia" (Pérez Gómez,1998).

Por ello es necesario reflexionar, comparar, confrontar, criticar, discernir entre lo manifiesto y lo aparente ,entre lo explícito y lo que subyace...

Siguiendo a Castells, en referencia al poder de las NTIC y a las desigualdades sociales , nos dice "... la sociedad de la información es aquella en la que el poder de nuestras tecnologías electrónicas y genéticas, amplifica, extraordinariamente, el poder de la mente humana y materializa en la realidad nuestros proyectos, nuestras fantasías, nuestras perversiones, nuestros sueños y nuestras pesadillas. Por eso es a la vez la sociedad de las proezas tecnológicas y médicas y de la marginación de amplios sectores de la población, irrelevantes para el nuevo sistema. Por ello estimula la creatividad de los niños al tiempo que satura su imaginario de videojuegos sádicos. Porque es un retrato de nosotros mismos, en toda su crudeza." (3)

Los autores Burbulles y Callister al referirse a Internet nos hablan de "riesgos y posibilidades".

¿Cómo llegar a ser usuarios críticos o hiperlectores?

"Mientras que los usuarios críticos están interesados en evaluar, poner en duda y juzgar en relación con sus fines la información que encuentran (...), el hiperlector está más dispuesto a desconfiar de los criterios y objetivos existentes, y a estudiar en qué grado dependen del contexto, es decir, no son absolutos; también está mejor preparado para actuar de manera creativa en la reestructuración e interpretación de los entornos de información y comunicación, en lugar de limitarse a aceptarlos o rechazarlos tal como son". 
Hiperleer significa, en este sentido, "ir más allá de las intenciones del creador (del sitio web), y no quedarse en el marco de las mismas".

Cuando el hiperlector observa con actitud crítica los enlaces, y no sólo el material que estos reúnen, logra un mayor nivel de capacidad crítica. A menudo se subestima la importancia de los links en un entorno intertextual; los puntos o nodos textuales se considera datos, y los enlaces, simple cuestión de preferencia o conveniencia ... no se repara en que el link también es un dato". Y más adelante agregan:

..."los links expresan sentidos, revelan preconceptos, impulsan o sugieren inferencias y, a veces, manipulan al lector".(4)

Romero Morante nos acerca sus reflexiones ."En efecto, ningún medio es educativo hasta que no se "construye" pedagógicamente. No lo es el ordenador, ni la televisión, ni un reproductor de videocintas, ni un mapa, ni un libro... sin su recolocación en nuevas coordenadas, con arreglo a pautas reguladoras que inscriben en ellos una intencionalidad y una modalidad de aprovechamiento instructivas. La recolocación supone, bien elaborar materiales ad hoc (software para aprender un contenido curricular, un programa televisivo para ejercitar algún idioma extranjero, un manual para primaria, etc.), bien idear una guía que permita insertar en una estrategia didáctica, al servicio de objetivos concretos, productos de procedencia extraescolar (un gestor de bases de datos para apoyar pequeñas indagaciones, o registrar información de personajes históricos; una antología poética para estimular el gusto por la lectura de este género y apreciarlo como manifestación de un clima cultural, o para medir la métrica, etc.). Esta impronta es necesaria y no arbitraria. Confiere viabilidad educativa al medio y, por tanto, es una precondición de uso. Yo la he denominado contextualización genético-constitutiva".

Y más adelante, relacionando los medios y su contextualización en la práctica educativa, señala:

"Lejos de ser usuarios pasivos, los profesores interpretan, filtran y reconducen tal carácter de acuerdo con sus preferencias, necesidades o sensibilidades, a su vez ligadas íntimamente a un sistema de creencias, convenciones, hábitos y normas relativos a la escuela, la propia asignatura, el aprendizaje, la inteligencia y "diversidad" de los estudiantes, el rendimiento académico, la metodología factible, los mecanismos de control y gestión de las clases, etc.

Por esa razón parece atinado ver en el medio, como hace Ben-Peretz (1990), un potencial curricular susceptible de ser rehecho, alterado o ajustado en cada aula, de conformidad con los esquemas (explícitos e implícitos) de pensamiento y acción de su responsable. En otras palabras, la aplicación del recurso configura igualmente su significación didáctica, toda vez que al decidir por qué, para qué o cómo utilizarlo (o por qué rechazarlo), el profesor lo "acomoda" a su cultura profesional, sus rutinas y circunstancias ambientales. Esta sería la segunda instancia contextualizadora, a la que he llamado contextualización práxica. A su través el medio se empapa asimismo en gramáticas, códigos y tradiciones pedagógicas, pues la práctica no es sólo una manifestación de estados subjetivos individuales sino también una creación sociohistórica: construimos nuestra práctica tanto como esa práctica es construida por la institución que la enmarca" (5).

\section{2. ¿POR QUÉ Y PARA QUÉ FORMAR DOCENTES CRÍTICOS DE LAS NTIC?}

Vamos a analizar aquí algunos paradigmas, ideas-fuerza, sobre los que apoyamos nuestra propuesta. 
¿Qué lugar ocupan los sujetos en estos procesos?

"Los sujetos sociales (hombres, niños, mujeres, obreros, campesinos, indígenas, jóvenes, inmigrantes y muchos otros) participan en situaciones educativas. Todas ellas tienen como finalidad coadyuvar a la constitución y al cambio del sujeto. (...) En el sistema educativo moderno siempre se trata de sujetos (educadores) que intentan incidir en otros sujetos (educandos) para lograr que se transformen en adultos, ciudadanos, amas de casa, dirigentes, sometidos, profesionales o lo que fuere.

(...) La educación como práctica productora de sujetos a partir de otros sujetos, es una mediación. Se realiza construyendo un sujeto mediador, que hemos llamado sujeto pedagógico. Con él nos referimos a la relación entre educador y educando, al producto de la vinculación entre los complejos sujetos sociales que ingresan a las situaciones educativas y los educadores, también sujetos complejos.

(...) Toda pedagogía define su sujeto. Cada una determina los elementos y el orden de las series que la constituyen como conjunto significante, cuya función es mediar entre los sujetos políticos y sociales, y el habitus que se pretende inculcar." (Puiggrós, Adriana,1990:30)

Siguiendo al Dr. Francisco Sierra( 2000), concebimos a la comunicación educativa dentro del Paradigma cultural: como un proceso contextualizado, de interacción, de reflexión y diálogo, de construcción cooperativa del conocimiento donde se valora el papel activo del sujeto, en el que las audiencias (llámense destinatarios, perceptores, "emirec") negocian significados que se pueden "apropiar o resistir", œmo dice Orozco(2001).

Surgen así las reflexiones sobre el rol docente, como mediador entre los objetos de conocimiento, la interacción, la interactividad con las NTIC, la posibilidad de intercambiar roles(emirec/ perceptor y emisor)

Desde esta función mediadora, se generan estructuras de significación en las que los receptores identifican ,decodifican y pueden deconstruir ideologías, valores, que son puestos en circulación.

Hablamos así de una Comunicación educativa basada en la empatía y en una comunicación multidireccional, en la que puedan participar todos los sujetos involucrados, desde una Educación dialógica, transformadora, abierta a la reflexión y a la creación de redes sociales.

Los Medios y las NTIC comprenden un proceso de investigación y reflexión sobre las representaciones, las ideologías, los valores, las formas de conocer, los discursos que desde ellos se propician y que ellos a su vez generan en lo que respecta a la decodificación de mensajes que realizan los destinatarios.

Las NT pueden contribuir a generar espacios para la construcción y reflexión. En este sentido, las comunidades de aprendizaje posibilitan llevar adelante procesos educativos integrados, participativos y continuos.

Desde la perspectiva socio-práxica: la concepción de una práctica educativa crítica implica considerar el contexto, tener en cuenta la realidad y cuestionarla.

Coincidimos con Edgar Morin (1999) quien nos dice que "... todo conocimiento necesita hoy reflexionarse, reconocerse, situarse, problematizarse..." 
Si analizamos los aportes de la Pedagogía crítica y la práctica educativa podemos observar, desde un enfoque retrospectivo, que tradicionalmente la concepción de la práctica educativa en Formación y Capacitación de docentes, estuvo descontextualizada de los procesos socioeconómicos y culturales.

Algunos pedagogos críticos se refieren a esta cuestión .

En este sentido Henry Giroux (1993) nos dice que las escuelas no están separadas del contexto socio cultural.

Son espacios de poder, sitios políticos donde se construyen discursos, significados y subjetividades.

Paulo Freire afirma: "Una concepción crítica y transformadora de la educación implica ser conscientes de algunas cuestiones ( $y$ actuar en consecuencia), el aprendizaje compartido (dialógico) y la participación en la toma de decisiones colectivas son componentes esenciales en una pedagogía transformadora

... una educación transformadora necesita desarrollar la crítica a lo existente, pero también las propuestas (en plural), así como una esperanza en las posibilidades de cambio mediante la implicación consciente y colectiva, y tanto a nivel de personas aprendices como de educadores y educadoras..." "La práctica docente crítica encierra el movimiento dinámico; dialéctico, entre el hacer y el pensar sobre el hacer". (6)

Carr y Kemmis (1988) afirman que los profesores necesitan de un cierto apoyo, la colaboración entre los profesores, con los formadores de profesores y con otras personas interesadas.

Proponen trabajar desde una metodología dialéctica crítica de formación, problematizadora de su propia práctica educativa.

Propiciamos formar, entonces, docentes reflexivos que adviertan por ejemplo, cómo actuar frente a procesos del "pensamiento único", parafraseando a Ignacio Ramonet (7) (que se encuentra y subyace en las instituciones educativas y en algunas propuestas didácticas presenciales y de Educación a distancia ) y la transmisión de mensajes a través de las NT., que operen con sus mediaciones entre la cultura, el lenguaje y la comunicación.

A través de los sistemas cibernéticos aparece la manipulación de imágenes y sonidos que utilizan técnicas como la digitalización, la infografía, la holografía, etc. Estos cambios tecnológicos producen efectos que inciden directamente en nuestras modalidades de comunicación tanto desde el plano individual como social y cultural.

En una entrevista realizada al Dr. Roberto Aparici, él nos dice:

"Se puede manipular la imagen, el sonido y el texto. Para que una manipulación funcione no debe ser visible. Si lo es, deja de funcionar como tal porque los espectadores se dan cuenta de que sucede algo extraño. Las estrategias de manipulación pueden surgir en una campaña premeditada, en comedias, en concursos..." ( 8)

Tomando las circunstancias de la guerra contra Irak, podríamos preguntarnos, por ejemplo: ¿qué imágenes recibimos en América Latina sobre la guerra? ¿ ¿Son las mismas que se transmiten en Europa $u$ otros países?.

Detengámonos un momento en el análisis de las imágenes y textos de la TV y lo que recibimos a través de la prensa escrita y digital... 
¿Cómo se ve la guerra en Internet? ¿cómo se muestra a los soldados, a las mujeres, a los niños, qué escenarios se muestran, aparecen visibles y cuáles no?

¿Por qué algunos sitios de Internet están bloqueados o son de lento acceso?

¿A qué se debe la falta de noticias en América Latina sobre la guerra, una vez decretado oficialmente el fin de la misma?.

La Educación no está aislada de lo que se vive en la sociedad.

Las representaciones de la realidad ya no son solamente lineales. Esto lo podemos observar en diversos medios como la televisión, el cine, el video o los multimedia, por citar algunos de ellos .

Para quienes pueden acceder a las nuevas tecnologías a través de los ordenadores personales con soportes de equipos multimedia, esto les permite adquirir la capacidad de producir sus propias imágenes, mensajes audiovisuales o electrónicos. De ser receptores pasar a ser emisores.

No obstante, vemos que aún existen muchos conos de sombras entre quienes no pueden acceder a las mínimas expresiones de las NTIC (por ejemplo, al correo electrónico).

Aquí aparecen los Inforricos e infopobres y la pregunta es si las NTIC disminuyen o acrecientan las diferencias, la denominada brecha digital, en la sociedad y particularmente en la Educación.

Consideramos de fundamental importancia que las instituciones educativas desarrollen la capacidad de criterio que permita discernir y aplicar valoraciones críticas sobre la información que nos llega como un constante fluir, tanto desde el mundo audiovisual como desde las Nuevas Tecnologías de la Información y Comunicación.

Planteadas de forma enumerativa, algunas de ellas pueden referirse a los roles del profesor en relación a los medios y NTIC; el dominio por parte de los alumnos de los lenguajes y códigos audiovisuales; la integración curricular de los medios en el proyecto educativo de las instituciones educativas; las modalidades de selección, producción y evaluación de medios y NTIC; la adaptación de éstos a las diferentes realidades educativas; el desarrollo de una actitud crítica y por tanto renovadora de los profesores y alumnos en relación a los medios y NTIC.

Así también resulta imprescindible desarrollar un análisis reflexivo y crítico sobre las consecuencias culturales y éticas que los cambios de las NTIC están propiciando en el proceso de aprendizaje, en las prácticas educativas y en los diversos contextos socioculturales.

Los docentes deberían reflexionar sobre cómo utilizar la Internet como apoyo dentro del salón de clases, en la biblioteca de la escuela y como recurso para desarrollar trabajos de investigación que puedan llevar a cabo tanto ellos como en equipo con sus alumnos.

Hacemos aquí hincapié no en el dominio procedimental, mecánico, del "saber hacer" que requiere navegar por Internet, sino en el hecho de comprender las posibilidades y las limitaciones de este recurso, como así también atender a las aplicaciones que de ella hacen sus alumnos: cómo seleccionan información, cómo la procesan y cómo se transforma en conocimiento. Éste implica la existencia de un sujeto y un proceso de construcción ,de adquisición, internalización y asimilación a partir de la experiencia, de la interacción con otros sujetos y con el medio, de la interpretación y reflexión, de la expresión, de la creación, la aplicación en diferentes contextos. 
Las TIC pueden ser entonces, herramientas para desarrollar habilidades cognitivas, comunicativas y cooperativas.

Para interpretar las distintas manifestaciones del lenguaje de los medios y Nuevas Tecnologías desde la práctica educativa, deberían incluirse estos contenidos en los planes de Formación y Capacitación docente que, a nivel terciario no universitario, en nuestra jurisdicción forman parte del currículo nulo.

Lo no enseñado, lo no aprendido.....o quizás lo aprendido desde los espacios de educación no formal, de autoaprendizaje, de educación continua.

Cabría preguntarnos entonces: ¿por qué no están incluidos estos contenidos en algunos Planes de estudio de Formación básica de docentes?

Pregunta que demanda repensar los diseños curriculares e incorporarlos a la formación básica de docentes...una asignatura pendiente en nuestra realidad inmediata.

Las Nuevas Tecnologías en sus distintos soportes, con una mirada atenta y reflexiva del docente, pueden ofrecer excelentes posibilidades pero somos conscientes también de sus limitaciones.

Un sitio web, por ejemplo, puede brindar un espacio de reflexión y construcción de conocimiento en el que las NTIC actúen como puentes comunicacionales que permitan a los receptores ser también emisores.

Distintas actividades de acceso a la información y comunicación con textos, imágenes, sonidos, como así también por ejemplo, la inclusión de un foro de discusión donde los destinatarios puedan incluir sus opiniones, proyectos, experiencias, aportes, acuerdos, disensos, etc.

Para ello se considera fundamental la inserción de propuestas y actividades que promuevan la interactividad tanto desde la composición y su soporte técnico hasta desarrollar procesos comunicacionales de ida y vuelta con un feed- back real y efectivo, teniendo en cuenta lo que Kaplún (1998) señala como Prealimentación, es decir, esa búsqueda inicial entre los destinatarios para que nuestros mensajes educativos los representen y reflejen, de manera que "cuando el mensaje es difundido, el sujeto colectivo puede reconocerse en él, aún cuando no haya participado directamente en su producción...Él es de alguna manera coautor del mensaje; comienza a hacerse emirec". ( 9 )

El pensamiento crítico está asociado al desarrollo de habilidades metacognitivas, de interpretación, de reflexión sobre el aprendizaje y también de la enseñanza.

Entonces, desde la reflexión-acción podríamos cuestionarnos ¿ qué actitudes tenemos hacia las Nuevas Tecnologías? ¿Cómo ven y cómo "viven" los docentes a inclusión de las NTIC en la práctica educativa?, ¿qué procesos de aprendizaje propiciamos?, ¿cómo podemos contribuir entonces a mejorar los procesos de aprendizaje y enseñanza a través de los medios y NTIC?, ¿qué evaluación realizamos de nuestras prácticas con las NTIC?.

¿Cuál es el rol docente esperado para formar lectores críticos de medios y NTIC?

¿Cómo desarrollar estos procesos en la práctica educativa?

Estos son algunos interrogantes que orientan nuestra investigación. 


\section{LA FORMACIÓN DE DOCENTES CRÍTICOS}

\section{Multimedia y sitio web: espacios interdisciplinarios de comunicación educativa y construcción del conocimiento, desde la Pedagogía crítica.}

En este trabajo ,una síntesis de la tesina desarrollada en el Master de la UNED en Nuevas Tecnologías de la Información y Comunicación, se desarrollan estrategias didácticas para formar docentes críticos, que operen con los Medios y Nuevas Tecnologías y reflexionen sobre su rol en la práctica educativa.

Los destinatarios directos de esta propuesta son docentes de todos los niveles y modalidades y estudiantes de carreras de Formación y Capacitación docente. indirectos : estudiantes de nivel polimodal y docentes de la orientación en Comunicación. Es decir, si bien originalmente están destinados a la Formación de Formadores, pueden participar otros destinatarios tales como los mencionados anteriormente.

A través de un sitio web y un multimedia se presentan diferentes propuestas interactivas ,para la construcción del conocimiento, desde la Pedagogía crítica.

En el marco de esta propuesta se concibe al sitio web y al multimedia como espacios de reflexión y construcción del aprendizaje, interdisciplinarios y compartidos con las posibilidades que ofrecen las Nuevas Tecnologías ,desde la concepción de Educación abierta.

Las NTIC nos permiten generar y construir espacios de comunicación alternativa y aprendizaje, de encuentros socio y multiculturales.

Se propicia una relación del usuario con su contexto, con otras personas o con otros usuarios, para poder compartir lo aprendido o experimentado y transferirlo a la realidad educativa formal y no formal.

La construcción de la conciencia colectiva de los docentes difícilmente puede abordarse desde las aulas, desde las instituciones educativas, caracterizadas por una distribución de tiempos y espacios "individualistas", donde los docentes corren sujetos al reloj, de escuela en escuela por los bajos salarios(al menos en Argentina)con pocos espacios para la discusión, reflexión compartidas y con intencionalidad marcada ,en nuestra realidad, de no propiciar espacios de reunión y comunicación en las instituciones educativas formales.

Pensar, reflexionar y comunicarse pueden resultar, a veces , una amenaza...

Los espacios y la gestión de instituciones educativas continúan siendo autoritarios, a pesar de que en el discurso propician prácticas democráticas.

\subsection{El sitio web "comunicarnos para aprender y construir"}

Se puede acceder a este sitio desde:

http://www.netverk.com.ar/ atedesco/

Sus objetivos son :

- Construir un espacio para la Formación y Capacitación docente, desde la Pedagogía crítica, a partir de la continua reflexión sobre la práctica educativa.

- Promover el desarrollo del trabajo colaborativo para la construcción compartida del conocimiento. 
- Propiciar proyectos de Educación y Nuevas Tecnologías en entornos virtuales de aprendizaje.

El punto de vista sobre el cual nos apoyamos para pensar en el proceso de diseño es el de pensar la web como un proceso de interacción humana, mediado por las Nuevas Tecnologías. Es decir, se concibe al sitio web como medio de comunicación entre las personas.

En este caso, entre docentes, estudiantes, profesionales, técnicos y audiencia en general que desee interactuar y participar en este proyecto.

Pensamos en el/los otros, los invisibles y desconocidos por conocer, a quienes va dirigido el sitio web.

En relación a los objetivos, nos preguntamos: ¿para qué?, o ¿qué deseamos que se produzca a partir de la publicación del sitio?

Se propone un modelo basado en el diálogo y participación, de manera tal que los destinatarios puedan aportar y construir conocimientos al proyecto en sus tres dimensiones: desde la dimensión didáctica (los contenidos, estrategias y actividades propuestas y evaluación),desde el modelo comunicacional propuesto y desde el enfoque tecnológico (en cuanto a su interacción con los medios y materiales: multimedia y sitio web).

El sitio web tiene en su estructura: áreas temáticas, una comunidad de aprendizaje y misceláneas.

Cuenta con un chat y un foro dentro de la Comunidad "Comunicarnos para aprender y construir". Esta comunidad se encuentra funcionando y participan en ella docentes del contexto Iberoamericano.

El sitio web tiene recursos tales como fotografías(de producción propia), comics y una producción en flash , éstos últimos cedidos por sus autores y productores.

\subsection{El multimedia "Educación, Nuevas Tecnologías y Globalización"}

Está pensado para su aplicación en las modalidades de Educación formal y no formal, en Educación a distancia y también en Educación de Adultos, donde se podrá complementar con estrategias didácticas participativas de Educación popular, que hagan más comprometida y solidaria a la relación de las personas con su ambiente y cultura local, generando proyectos comunitarios de educomunicación alternativa, de reflexión/ acción/ reflexión.

En este multimedia se intenta desarrollar la reflexión, atender a los mensajes que al receptor lleguen, llevar a un proceso en el que los sujetos puedan elaborar, interpretar, construir otros conocimientos, arribar a conclusiones que puedan transferir en su práctica educativa y la incorporación de estos resultados en el sitio web, que se articulará y complementará con este material.

No se espera una respuesta o respuestas correctas de los usuarios sino, por el contrario, se incluyen y aceptan todas las interpretaciones, producciones y significados múltiples que se puedan construir.

Una de las estrategias pensadas para este multimedia es el desarrollo de comunicación, de búsqueda, descubrimiento, curiosidad, creatividad, de favorecer otros mensajes y nuevas opciones de socialización e intercambio. 
Esta es una de las posibilidades de la dimensión social y comunitaria de este proyecto.

Otra de las posibilidades para generar comunicación a partir del Multimedia, es incluir enlaces a Internet hacia sitios relacionados con alguno de los temas en particular, (imágenes, música, otros) y también propiciar la búsqueda de los propios usuarios que podrán compartir con otros destinatarios algunos recursos internos del sitio web como foros o chat, de comunicación asincrónica y sincrónica respectivamente.

Los núcleos temáticos que componen este multimedia son:

- Medios, mediaciones y representaciones:

Desde la Educación en medios, las mediaciones y representaciones sobre las que puede el docente ejercer su influencia como promotor de procesos de aprendizaje constructivistas y en relación con los procesos históricos socioeconómicos y culturales.

- Globalización en los medios y Nuevas Tecnologías:

Desde la lectura crítica y representación de mensajes en los medios y Nuevas Tecnologías sobre la globalización y sus influencias en el contexto global, local y "glocal"

- Pedagogía crítica y práctica educativa:

Desde la práctica educativa y la pedagogía crítica, en tanto que implica una transformación del rol docente, más comprometido, no solo como receptor o reproductor de procesos sino como productor de nuevos mensajes y significados.

- Pensar, descubrir, imaginar, construir...:

Desde un espacio de sueños y utopías que he denominado "Pensar, Imaginar, ...construir"queda abierta una instancia para trabajar con las utopías. Es un espacio abierto para la creatividad a partir de distintas producciones como poemas, cuentos, videos y otros que puedan elaborar los destinatarios con la posibilidad de incluirlos en el sitio web.

En esto también participa el usuario activamente, como productor de significados con respecto a la evaluación que realiza sobre este material (y también desde su participación en el sitio web)

\subsection{La evaluación}

Se intenta buscar al máximo el aprovechamiento pedagógico de este material y entender al proceso de evaluación del mismo en forma permanente.

Se sugiere un modelo de evaluación abierta, basada en construcciones y criterios cualitativos más que cuantitativos. Es decir, que la aplicación en su funcionamiento, con sus fortalezas y debilidades, sus posibilidades y limitaciones sea evaluada permanentemente por los usuarios.

La evaluación es concebida, además, como un proceso consensuado ,participativo y compartido, acorde con la concepción de emirec.

Interesa, por lo tanto, que los sujetos que participan en la experiencia construyan y produzcan significados sobre la evaluación.

La evaluación simboliza atributos del poder: quien maneja la información y sabe qué sucede en un proceso puede tomar decisiones en distintos sentidos y con diferentes variantes. 
En el modelo que se propone, la evaluación es inclusora, pues desde el diseño de la propuesta y de los materiales se da la posibilidad de intervención de los sujetos y se propicia una devolución de la información obtenida, a través de modalidades de retroalimentación(por mail, foro y chat).

Se proponen estrategias metacognitivas y autorreguladoras a través de las cuales los destinatarios puedan identificar sus propios procesos de aprendizaje y a través de la interacción con los materiales(multimedia y sitio web) puedan descubrir otras modalidades de aprendizaje (resolución de problemas, cooperación y colaboración con otros sujetos en trabajos grupales cooperativos ,en los que se desarrolle el pensamiento crítico, la argumentación, la discusión e interpretación)

Se propicia la autoevaluación de los destinatarios y del propio evaluador o evaluadora.

En este modelo de evaluación, se tratará de incluir y explorar tanto los aspectos manifiestos como los implícitos.

También se reflexiona sobre el rol del evaluador en cuanto "portador" de un modelo de evaluación, ya sea explícito o implícito.

Además está prevista una revisión y reflexiones sobre el modelo propuesto y el propio proceso de evaluación, es decir, "evaluación de la evaluación" o la meta-evaluación.

La evaluación nos permite no solamente conocer el nivel de aprendizaje , en este caso de acuerdo al proyecto ,sino también cómo es la interacción de los destinatarios con los materiales y también encontrar los errores del proceso docente como mediador entre los objetos de conocimiento, los materiales y los destinatarios; en este sentido la evaluación tiende a la mejora de la propuesta.

\section{CONCLUSIONES}

La inserción de las Nuevas Tecnologías en la Educación nos hace reflexionar desde distintos paradigmas.

Desde la práctica educativa y profesionalización docente, el desarrollo de estrategias didácticas y evaluación puede ser un núcleo central para tratar el tema de las audiencias docentes, pues serán estos actores quienes trabajarán con niños, jóvenes y adultos.

Las Nuevas Tecnologías de la Información y Comunicación pueden ofrecer alternativas para gestionar e instalar prácticas educativas basadas en los procesos de construcción del conocimiento.

Podrá ser entonces propicia la oportunidad para desarrollar otro modelo de audiencia, más activa, crítica y participativa, desde los propios perceptores.

Nos planteamos para qué y cómo utilizamos las Nuevas Tecnologías en Educación, qué significados podemos construir con y desde ellas, cómo intervenir en nuestra práctica educativa, desde la reflexión y acción en nuestro rol docente, como profesionales comprometidos de la Educación, con nuestro tiempo y nuestra cultura.

También podemos investigar cuáles son las teorías del aprendizaje y la comunicación educativa que subyacen en cada propuesta pedagógica, las actitudes de la audiencia ,su reconocimiento como sujetos dialógicos ,sus intervenciones, sus producciones, sus procesos de comunicación educativa. 
En la extensa bibliografía sobre estas temáticas queda aún mucho por investigar en lo que respecta al desarrollo de estrategias que posibiliten una actitud crítica, de participación y no solo de recepción cuando nos involucramos con las Nuevas Tecnologías con una finalidad pedagógica.

¿Cómo hacer entonces para que la audiencia receptora se transforme en productora, basada en sus propias necesidades individuales y sociales, donde se construyan vínculos de cooperación, participación y solidaridad, traspasando el modelo que nos quieren imponer desde el "afuera" que invade nuestros mundos, espacios y tiempos, con ataques subliminales que limitan la capacidad de elección (por un lado) y activan tendenciosamente a dirigirse a consumir, opinar o actuar de determinada manera?

En esta propuesta los usuarios son docentes, muchos de ellos con pocas posibilidades de acceso a multimedia e Internet tanto desde los costos como del grado de acercamiento o amigabilidad hacia estos materiales, y con pocas( por no decir nulas) oportunidades de utilizar o participar en la producción de aquellos diseñados especialmente para actividades de Formación y Capacitación docente. A ello se agrega la poca rentabilidad de estos materiales, como una de las causas que no lo hacen prosperar en el mercado o en las instituciones educativas.

Podríamos decir que son sus alumnos quienes están más familiarizados para usar multimedia comercializados (por ejemplo, determinadas enciclopedias incluídas en kit de equipos de computación).

Desde ya que muchas veces éstos últimos se utilizan sin un análisis crítico de la veracidad de la información o el desarrollo y presentación de los contenidos.

Se deberá, entonces, reflexionar y distinguir sobre la información y el conocimiento.

En Formación y Capacitación de docentes, será importante también, incluir las temáticas en los diseños curriculares .

Estos últimos, lamentablemente no son más que prescripciones: corren por una vía y las necesidades de formación de los docentes, por otra.

A ello se agrega que los espacios de poder se hacen sentir en la toma de decisiones ,a la hora de incluir o no ciertos contenidos.

No es casual(sí causal) que no se encuentren en algunos planes de estudio de formación docente, reflexiones sobre las Nuevas Tecnologías y el proceso de globalización, por citar solo un ejemplo de contenidos ausentes o también llamados de "currículum nulo" por algunos autores.

Las concepción que se tiene de las prácticas educativas en los modelos de Formación y capacitación en la realidad ,es de aislamiento con respecto a los fenómenos socioeconómicos y culturales que impregnan a toda acción educativa (el tema de la globalización, de las influencias de la tecnología en la sociedad y particularmente en educación, por citar algunos ejemplos)

Otra "asignatura pendiente" en la formación de docentes...

El aula, presencial y virtual, puede ser un espacio de construcción de saberes y diálogos, un escenario propicio para desarrollar redes de aprendizaje, procesos de construcción y reflexión crítica.

Orientar para elegir en libertad será entonces un desafío entre las posibilidades de acceso a los medios y NTIC y entre las alternativas mencionadas anteriormente. 
Queda mucho por transitar y quizás deberíamos recuperar más los espacios de educación no formal: lo que no se da dentro de la institución educativa (sea Instituto, Facultad, Colegio, centro educativo) ni está previsto desde las políticas educativas, habrá que gestarlo fuera de ella, desde una educación alternativa.

Es aquí donde los educadores, utilizando las Nuevas Tecnologías desde una perspectiva crítica podemos interactuar construyendo "puentes comunicacionales" entre las audiencias, promoviendo espacios públicos de participación y educación, auténticas redes de comunicación y aprendizaje.

Las Nuevas Tecnologías no representan por si solas la panacea, la fórmula mágica que sí o sí generará procesos significativos de aprendizaje .

Tanto en su diseño, producción e implementación y evaluación se deberán articular con una propuesta pedagógica, contextualizada y enmarcada según la intencionalidad educativa u objetivos que se pretende lograr.

Si se llega a esta concientización (que desde ya implica un trabajo sistemático e inserto en un proyecto pedagógico integral)podremos pensar en que estos usuarios se transformen de reproductores a constructores y productores críticos.

Las Nuevas Tecnologías pueden ofrecer espacios de comunicación alternativa y aprendizaje, de encuentros socio y multiculturales.

La experiencia transitada durante los dos años del Master en Nuevas Tecnologías de la Información y Comunicación de la UNED de Madrid bajo la dirección de Roberto Aparici y su equipo de colaboradores, me ha permitido pensar en la posibilidad de experimentar otras alternativas críticas, de explorar nuevos caminos, tanto desde la conceptualización teórica, la reflexión e interpretación, como desde los procedimientos para diseñar, producir y evaluar aplicaciones con las Nuevas Tecnologías.

Otro punto a considerar es la mirada atenta y crítico/ reflexiva que los docentes puedan lograr o desarrollar ante la cultura del marketing comercial que existe y va en aumento de consumos de productos multimedia comercializables.

Aprender a elegir, a seleccionar material,(lo que aquí, para este trabajo llamamos "electores") a producir nuevos significados y por qué no a analizar estas producciones comerciales a través de redes de docentes que interactúen con sus intercambios y con una participación activa.

Suele suceder que hay que usar tal o cual material porque lo impone alguna Reforma( $¿$ ?) educativa, porque lo impone autoritariamente el sistema o porque está de moda!!.

El hecho de transformarse en docentes críticos implica también asumir desde la investigación/ acción un rol protagónico, en el que sea posible evaluar situaciones de aprendizaje con los medios y NTIC , tanto el proceso como los resultados de éste.

Ello incluye, además, atender a las posibilidades y limitaciones técnicas, comunicacionales y pedagógicas.

¿Cómo podemos participar?

- Unir teoría-práctica como procesos de investigación, sistemáticos y críticos sobre la enseñanza y el aprendizaje con las NTIC. 
- Promover una cultura de colaboración, donde todos los actores estén continuamente aprendiendo a enseñar y a la vez investigar sobre su propia práctica educativa.

- Compartir y construir el conocimiento entre los docentes, en equipos interdisciplinarios.

- Generar espacios interactivos y trabajar colaborativamente .

Vamos avanzando...pensamos también en docentes que puedan reconocer y saltar los mitos de las NTIC, romper con los estereotipos y patrones standard que circulan en las instituciones educativas y fuera de ellas, en acciones no formales.

Docentes que reflexionen sobre sus propias prácticas, que puedan elegir, criticar, construir y también resistir con argumentos sólidos y confiables.

Estos son algunos de nuestros desafíos...

\section{NOTAS}

(1) Reinoso, Susana "Educación para los medios: un desafío de hoy", La Nación line, 6/10/96).Entrevista a Roberto Aparici .

(2) Trejo Delarbre, Raúl (1996). La nueva alfombra mágica. México, Ed. Diana-Fundesco.

(3) Castells ,Manuel 1998. La era de la información. Vol. 1 La sociedad red .Alianza Editorial. Madrid.

(4) Burbules, N. Y Callister, T(h).(2001) Educación: riesgos y promesas de las Nuevas Tecnologías de la Información. Ed. Granica, Barcelona, España.

(5) Romero Morante Jesús. Tecnologías informáticas, nuevas formas de capital cultural e innovación en la enseñanza de las ciencias sociales. Scripta Nova Revista electrónica de geografía y ciencias sociales .Universidad de Barcelona.

Dirección:http://www.ub.es/geocrit/sn/sn-107.htm

(6) Freire, Paulo (1997) Pedagogía de la autonomía. Siglo XXI Editores. México;39.

(7) Ramonet, I. (1998). Pensamiento crítico versus pensamiento único. Madrid. Ed. Le Monde Diplomatique. Temas de debate. 2da edición.

(8) Entrevista a R. Aparici ,por Fernando del Busto,"La voz de Avilés", 21/03/03. Dirección:http://servicios.elcomerciodigital.com/pg030221/prensa/noticias/Aviles/200302/21/GIJ-AVI$\underline{065 . h t m l}$

(9) Kaplun, M.(1998). Una pedagogía de la comunicación, Madrid: Ediciones de la Torre, 79.

\section{BIBLIOGRAFÍA}

APARICI, Roberto (coord.) (1996): La Revolución de los Medios Audiovisuales. Educación y Nuevas Tecnologías. 2. ${ }^{a}$ edición. Ediciones de la Torre. Madrid.

AyUSTE, Ana ; Flecha, Ramón; López Palma, Fernando; Lleras, Jordi. Planteamientos de la Pedagogía Crítica. Comunicar y transformar. Edit. Grao, Barcelona, 1994. 
CARR, W. Y KEMMIS, S. (1988). Teoría Crítica de la enseñanza, la investigación-acción en la formación del profesorado. Barcelona: Ediciones Martínez ROCA,S.A.

Gimeno SACRistán, J. y PÉREZ Gómez, A. (1989) La enseñanza. su teoría y su práctica. Ed. Akal Universitaria. Madrid.

GIROUX, H. A.; (1990) Los profesores como intelectuales. Hacia una pedagogía crítica del aprendizaje. Barcelona, Paidós.

GIROUX, HENRY O. (1993) La escuela y la lucha por la ciudadanía: pedagogía crítica de la época moderna. 1. ed. México: Siglo Veintiuno.

HABERMAS, (1987)Teoría de la Acción Comunicativa. I, Taurus, Madrid.

MORIN, E.(1999). La cabeza bien puesta. Bs. As, Nueva Visión.

MORIN, Edgar, (1996) "En el pensamiento complejo contra el pensamiento único", entrevista realizada por Nelson Vallejo Gómez, en Sociología y Política, Nueva época, año IV,núm.8,México.

MARI SÁEZ, V(1999). Globalización, nuevas tecnologías y comunicación, Madrid: Ediciones de la Torre

Orozco GómeZ ,G. (2001)Televisión, audiencias y educación. Buenos Aires, Grupo editorial Norma, 82.

PÉREZ GómeZ, Angel I. (1997) "Socialización y Educación en la época Postmoderna".En: BERNSTEIN, B y otros autores. Ensayos de Pedagogía Crítica. Madrid, editorial Popular.

PUIGGROS, Adriana (1990) Sujetos, disciplina y curriculum en los orígenes del sistema educativo argentino. Buenos Aires: Galerna,. Pág. 30

SIERRA CABALLERO ,Francisco(2000). Introducción a la teoría de la comunicación educativa. Sevilla, Editorial MAD. 